\title{
Early detection of brain damage in emergency department and the organ donation process: a case series
}

\author{
İskender Aksoy¹, Mehtap Pehlivanlar Küçük², Çağatay Erman Öztürk², Ahmet Baydın ${ }^{1}$ \\ ${ }^{I}$ Department of Emergency Medicine, Ondokuz Mayss University School of Medicine, Samsun, Turkey \\ ${ }^{2}$ Department of Anesthesiology and Reanimation, Division of Intensive Care Medicine, Ondokuz Mayls University School of Medicine, \\ Samsun, Turkey
}

DOI: $10.18621 /$ eurj.377090

\begin{abstract}
Brain death is defined as the irreversible loss of brain function following various pathophysiological changes. In many countries, the brain death diagnosis is carried out in conjunction with organ transplant programs. In Turkey, at third level health institutions in particular, healthcare units established entities that follow similar procedures. The increased number of patients waiting for organs and donor discovery studies have enhanced the public's interest in this topic. Since the emergency department is usually the first line in admitting patients, its staff must have the firsthand knowledge of managing brain death and organ donation process. In this article, we present three clinical cases that we followed and diagnosed with brain death in our emergency department. Due to the lack of studies addressing brain death procedures in the emergency service, we believe that this report will greatly contribute to our awareness and handling of brain death treatment.
\end{abstract}

Keywords: Brain death, emergency medicine, organ donation

Received: January 10, 2018; Accepted: March 11, 2018; Published Online: April 12, 2018

B rain death is characterized by the irreversible loss of all brain functions, including the brain stem. Diagnosis of brain death is made following clinical determination of deep coma, absence of brainstem reflexes, and apnea test [1]. Emergency rooms (ERs) are the first line of care and where immediate interventions happen. Therefore, it is important to have diagnosing procedures for brain deaths in the ER. In this article, we aimed to draw attention to the procedures for brain death diagnosis in patients with prolonged stay in the ER as a result of limited space in the intensive care unit (ICU). The organ donation process and the process of determining appropriate organ donors will also be discussed.

\section{CASE PRESENTATION}

\section{Case 1}

A 57-year-old female was admitted to our ER with persistent headache and did not respond to analgesic treatment. The patient's history indicated that she was diagnosed with hydrocephalus with normal pressure and had nausea-vomiting, forgetfulness, and urinary incontinence during the last 3 days. The patient's Glasgow Coma Scale (GCS) was 15 at the time of admission. During the follow-up, the patient developed a respiratory arrest, was intubated, and put on mechanical ventilation support. The routine blood tests did not show any abnormalities except for

Address for correspondence: Isskender Aksoy, MD., Ondokuz Mayls University School of Medicine, Department of Emergency Medicine, 55100 Samsun, Turkey

E-mail: driskenderaksoy@hotmail.com,Phone: +90 5458961555

Copyright (C) 2018 by The Association of Health Research \& Strategy

Available at http://dergipark.gov.tr/eurj 
hyponatremia (Na: $126 \mathrm{mEq} / \mathrm{L})$. The brain computed tomography (CT)scan revealed hydrocephalus (Figure 1a). External ventricular drainage was performed by the neurosurgeon. Since there was no room in the ICU, the patient was taken to the ER ICU. The patient's hyponatremia was treated with hypertonic $\mathrm{NaCl}$. On the third day of hospitalization, the patient's sodium levels reached $138 \mathrm{mEq} / \mathrm{L}$. The patient was monitored with the mechanical ventilation without sedation and, at the end of the third day, her GCS was assessed, which was stable at 3 . The patients' GCS stayed at 3 and brain death test was initiated. The result of the apnea test was positive. After brain CT angiography and detailed neurological examination, the diagnosis of brain death was finalized. The ER physician informed the family that the patient was brain dead. Afterwards, our hospital's donor organ transplant coordinator informed the family about organ donation. However, the family did not wish to donate the patients' organs. On the 4th day of the hospitalization, the patient died after cardiac arrest.

\section{Case 2}

A 64-year-old male patient was referred to our ER following intubation at another healthcare facility. The referring physicians informed us that the patient had a headache and suddenly collapsed after feeling weakness on his left side. His history included hypertension. The physical examination did not reveal light reflex. The patient's blood pressure was 180/100 $\mathrm{mmHg}$ at the time of admission, and he was administered intravenous esmolol. Routine blood test revealed hyponatremia $(\mathrm{Na} 133 \mathrm{mEq} / \mathrm{L})$. The brain CT showed a hematoma at the level of the right basal ganglia (Figure 1b). External ventricular drainage was performed by the neurosurgeon. Since there was no room in ICU, the patient was placed in the ER ICU. The patient's serum creatinine level was $4.97 \mathrm{mg} / \mathrm{dl}$ and his blood sodium level was $159 \mathrm{mEq} / \mathrm{L}$. Following a hydration treatment, the patient's serum creatinine level dropped to $1.04 \mathrm{mg} / \mathrm{dl}$, and serum sodium level declined to $143 \mathrm{mEq} / \mathrm{dl}$. The patient's sedation was stopped at an early period and, on the 5th day of hospitalization, his GCS was assessed at three. The neurological and ICU evaluated the patient for brain death. The apnea test result was positive. The neurological examination did not detect any brain stem reflexes. Transcranial Doppler ultrasonography (DUSG) was performed as a confirmatory test, and showed low-speed diastolic negative current in the form of systolic spike in both internal carotid and vertebral arteries. Flow was not detected in intracranial vascular structures, anterior cerebral artery, and/or middle cerebral artery. Clinical examination and supportive imaging scans were used to diagnose brain death. The family was informed about the patient's brain death and the hospital donor organ transplant coordinator informed the family about organ donation. The family declined organ donation. On the 6th day of hospitalization, the patient died due to cardiac arrest.

\section{Case 3}

A 59-year-old female was admitted to our ER with a sudden headache and blurring consciousness. At the time of the admission, her GCS was assessed as eight. The patient had no known disease other than hypertension. The brain CT showed hemorrhagic

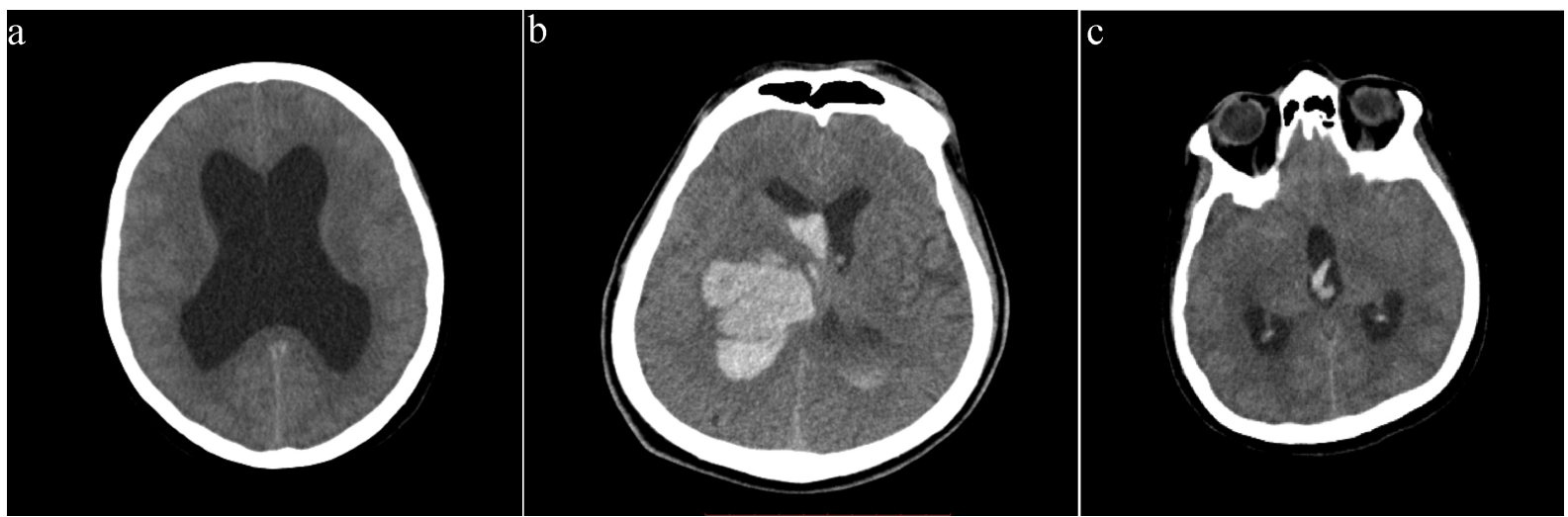

Figure 1. Patients' brain computed tomography images. 
densities in peri-mesencephalic cistern, prepontinecistern, basal cisterns, and in third and fourth ventricular lumens (Figure 1c). External ventricular drainage was performed by the neurosurgeon and brain edema therapy was initiated. Due to the lack of room in the ICU, the patient was placed in the ER ICU. After approximately 6 hours, the patient developed cardiac arrest. After a 10-minute long successful cardiopulmonary resuscitation, the patient achieved a normal sinus rhythm. A follow-up brain CT scanshowed additional hemorrhages in lateral ventricles. The patient was assessed, and her GCS level was three. The patient did not receive sedation, and 24 hours later was subjected to an apnea test. The apnea test performed in the ER was positive. The transcranial DUSG showed low-rate, high-resistance, and diastolic negative current in both internal carotid arteries. No flow was observed in the intracranial vascular structures. Clinical examination and supportive imaging scans were used to diagnose brain death. The ER doctor informed the family about patient's brain death. Afterwards, our hospital's donor organ transplant coordinator informed the family about the possibility of organ donation. However, the family declined to donate the patient's organs. The patient died after cardiac arrest on the third day of hospitalization.

\section{DISCUSSION}

The most common causes of brain death in adults are: traumatic brain injury, intracerebral hemorrhage, subarachnoid hemorrhage, hypoxic brain injury, and ischemic stroke [2]. It is often observed as a result of the increased intracranial pressure following a traumatic intracranial injury.

Brain death is characterized by the irreversible loss of all activities of the brain, brainstem, cerebellum, and the remaining parts of the central nervous system located within the skull. In accordance with the viewpoint of our society, the Turkish Neurological Society considers the concept of brain death as "whole brain death" [1]. In Turkey, the Law on "Regulation of Removing, Storing and Transplant of Organs and Tissues" and "Turkish Ministry of Health's Guidelines on Organ and Tissue Transplantation Appendix 1explain the legal aspects of brain death $[3,4]$. These guidelines state that brain death can only be confirmed based on medical evidence and by an unanimous decision made by a group of doctors comprised of neurologist/neurosurgeon, and an anesthesiologist/ICU specialist.

ERs have a fast turnover rate whereby early interventions and treatments are performed. Brain death is more common in patients admitted to ER and the central nervous system pathologies progressively worsened after intervention. Often, however, these patients are often lost before any diagnosis is made from them or they are taken into surgery and placed in the corresponding ICU following surgery. For these reasons, it is very difficult to track brain death and organ donation stages in accidents and emergency services. It is therefore not possible to make a sound and informed follow-ups especially for end-of-life care and towards the stages of organ donations.

Different rules apply to the evaluation of prognosis of the patients with brain damage. However, there is no established guideline with regard to how and when to apply those rules to day-to-day clinical practices. In 2015, Neurocritical Care Society has

Table 1. The patients' apnea test results

\begin{tabular}{llcccccc}
\hline & \multicolumn{2}{c}{ Case 1 } & \multicolumn{2}{c}{ Case 2 } & \multicolumn{2}{c}{ Case 3 } \\
\hline \multicolumn{2}{l}{$\begin{array}{l}\text { Age (year)/Gender } \\
\text { GCS at admittance }\end{array}$} & \multicolumn{2}{c}{$57 /$ Female } & \multicolumn{2}{c}{$64 /$ Male } & \multicolumn{2}{c}{$59 /$ Female } \\
\multicolumn{1}{l}{ Results of the } & $\mathrm{pH}$ & Before & After & Before & After & Before & After \\
apnea test & 7.35 & 7.11 & 7.45 & 7.25 & 7.35 & 7.16 \\
& $\mathrm{pCO}_{2}$ & 36 & 63 & 36 & 57 & 35 & 70 \\
& $\mathrm{pO}_{2}$ & 482 & 434 & 209 & 282 & 241 & 110 \\
& $\mathrm{HCO}_{3}$ & 22.1 & 16.1 & 23.2 & 21.9 & 20 & 19.9 \\
& $\mathrm{SO}_{2}$ & 99 & 99 & 97 & 99 & 99 & 99 \\
\hline
\end{tabular}

GCS $=$ Glasgow coma scale 
suggested to postpone any decisions regarding end-oflife care for brain damaged patients within the first 72 hours in order not to miss any chance of positive outcomes regardless of how big they might be [5]. The mentioned time corresponds the time when the patients are first seen in emergency services, and therefore it is vital to increase awareness on organ donation in ERs.

The end result of our hospital's organ transplant coordination team was to work to increase awareness and sensitivity regarding organ transplantation. In the past 2 years, 65 cases of brain death were diagnosed and organ donation resulted in $23(35 \%)$ cases. In the entire country, there were 3,847 cases of brain deaths and $1,074(28 \%)$ organ donations in the last two years [6]. The average organ donation numbers of our hospital were above Turkey's average. As a part of the organ transplant coordination team, our ER carefully assesses patients with high probability of mortality and patients with severe head trauma in terms of brain death and possible organ donation after the first intervention. Moreover, immediate communication with the ICU was established.

As observed in the above presented three cases, unresponsive patients cannot be transferred to the ICU and must stay at the ER. Similarly, a new study reports that initiation of end-of-life care in acute settings and lack of knowledge and experience in organ donation practices outside ICUs results in under of patients who could potentially donate [7].

The physician in charge of the ER should suspect brain death and should initiate appropriate diagnostic procedures. The patient should meet certain conditions before the diagnosis of brain death is made. First of all, the diagnosis of the cause that may have led to brain death must be confirmed. The presence of irreversible severe structural brain injury must be demonstrated by an imaging method (brain CT or magnetic resonance imaging). There should bean unresponsiveness to all treatment interventions, systolic blood pressure should be $\geq 100 \mathrm{mmHg}$ (this condition can also be achieved with vasopressor support), central body temperature should be $\geq 36^{\circ} \mathrm{C}$, and there should be an electrolyte imbalance and/or metabolic disturbance that would prevent brain stem reflexes. In addition, the patient should not be under the influence of any drugs that may affect the level of consciousness. After these conditions are met, brain death must be confirmed with clinical cardinal findings. These findings include deep coma with complete absence of response (GCS: 3 ), loss of brain stem reflexes (light reflex, corneal reflex, oculocephalic reflex, vestibulo-ocular reflex, and retching and cough reflex), no spontaneous respiratory movements, and verified positive apnea test. If there are any findings that suggest brain death after the first neurological examination, a second examination should be performed after a certain time tosee if there areany changes in those findings. This waiting period is 48 hours in infants younger than two months, 24 hours in children between 2 months and 1 year, 12 hours in children over 1 yearto adults, and 24 hours in patients that have undergone CPR. In cases where cardinal findings of brain death are shown in the first examination, there is no need to complete the waiting period if supportive evidence and cerebral circulatory arrest are indicated (1). In our study, the aforementioned preconditions were met in all three patients, the apnea test was positive (Table 1), and following the results of supportive testing (brain CT angiography in one patient, transcranial DUSG in the other two patients) the diagnosis of brain death was confirmed. Subsequently, with the cooperation of the organ transplant coordinator, neurology, and the ICU, the relatives of the patient were informed about brain death and the option of organ donation was discussed. However, the families of all three of our patients did not accept organ donation. Due to the rapid patient flow in the ER and limited communication time with patient relatives, it is very difficult to manage the organ donation process. In cases where brain death and subsequent organ donation is a possibility, it is very important to develop a relationship with the relatives of the patient in order to establish trust between the physician and the family.

Increase in organ transplantations depends on increases in number of donations. Research show that certain factors have impact on organ donations and these factors are influenced by psychological, sociological, demographic, cultural and religions thoughts. It was also found related to thoughts about organ donations, and knowledge on how the system works and media's impact. In the sense, it is important to understand that the terms of organ donation and organ transplant are multi-discipliner concepts. Therefore it is important to recognise the concepts like 
brain death, organ donation and organ transplant, and its social aspects in the process of making a decision on becoming a donor $[8,9]$. Previous studies have shown that organ donors in the United States and other European countries are missed in the emergency department $[10,11]$. We believe that, as ER physicians become more experienced in this area, the success rate of donation acceptance will increase in patients that are suitable for organ donation.

\section{CONCLUSION}

The patient in the course of brain death should be monitored very closely regardless of the possibility of organ donation. The detection and close monitoring of these patients should be initiated in the ER. After the possible candidates are identified in ER, the intensive care and organ transplant coordination team should be informed and their experience in this process management should be utilized. Although proper initial treatment, effective resuscitation, and close follow-up cannot always save the life of a patient, they can direct the process in terms of preserving the organs for the donation process. For this reason, although every emergency physician's goal is to save lives, they also should keep in mind the possibility of brain death and organ donation in patients with poor prognosis. This is especially true for those with isolated central nervous system damage.

\section{Informed consent}

Written informed consent was obtained from the patients for the publication of this case series

\section{Conflict of interest}

The authors declared that there are no potential conflicts of interest with respect to the research, authorship, and/or publication of this article.

\section{Acknowledgements}

We would like to acknowledge the www.makaletercume.com and Dr. Merih Fidan Bektaş or their outstanding scientific proofreading and editing services that was provided for this manuscript.

\section{REFERENCES}

[1] Arsava EM, Demirkaya Ş, Dora B, Giray S, Gökçe M, Güler A, et al. [Turkish Neurological Society - Diagnostic guidelines for brain death]. Turk J Neurol 2014;20:101-4. [Article in Turkish]

[2] Nathan S, Greer DM. Brain death. Semin Anesth Perioper Med Pain 2006;25:225-31.

[3] Organ ve Doku Alınması, Saklanması, Aşılanması ve Nakli Hakkında Kanun, Pub. L. No. 2238 Stat. 16655 (29/5/1979).

[4] Organ ve Doku Nakli Hizmetleri Yönetmeliği Stat. 28191 $(01 / 02 / 2012)$.

[5] Souter MJ, Blissitt PA, Blosser S, Bonomo J, Greer D, Jichici D, et al. Recommendations for the critical care management of devastating brain injury: prognostication, psychosocial, and ethical management: A Position Statement for Healthcare Professionals from the Neurocritical Care Society. Neurocrit Care 2015;23:4-13.

[6] Organ, Doku Nakli ve Diyaliz Hizmetleri Daire Başkanlığı Resmi Sayfas1 [cited 2017 01/12/2017]. Available from: https://organkds.saglik.gov.tr/KamuyaAcikRapor.aspx?q=YOBIS.

[7] Witjes M, Kotsopoulos A, Herold IHF, Otterspoor L, Simons KS, van Vliet J, et al. The influence of end-of-life care on organ donor potential. Am J Transplant 2017;17:1922-7.

[8] Sever M. [Problems and solution suggestions in renal transplantation in Turkey]. Türk Nefroloji Diyaliz ve Transplantasyon Dergisi 2008;17(Suppl 1):3-8. [Article in Turkish]

[9] Kahveci E, Topçuoğlu BCV. Beyin ölümünden organ nakline - temel ilkeler ve pratik uygulamalar. Özyurt Matbaacılık: Ankara., 2015.

[10] Le Conte P, Riochet D, Labastire L, Auneau JC, Legeard E, Van Tricht M, et al. Identification of potential organ donors of advanced age in EDs. Am Emerg Med 2012;30:170-3.

[11] Riker RR, White BW. Organ and tissue donation from the emergency department. J Emerg Med 1991;9:405-10. 